\title{
Effect of Storage Time and Packing Method on the Freshness of Dried Lycium Fruit Using Electronic Nose and Chemometrics
}

\author{
Xiaojing Tian $\mathbb{D D}^{1,2}$ Ming Long, ${ }^{1,2}$ Yuanlin Liu $\mathbb{D}^{1,2}$ Peng Zhang $\mathbb{C D}^{1,2}$ Xiaoqin Bai, ${ }^{1,2}$ \\ Jun Wang $\mathbb{D},{ }^{3}$ Zhenbo Wei, ${ }^{3}$ Shien Chen, ${ }^{1,2}$ Zhongren Ma $\mathbb{D}^{1,2}$ Li Song $\mathbb{D},{ }^{4}$ and Li Luo ${ }^{4}$ \\ ${ }^{1}$ China-Malaysia National Joint Lab, Biomedical Research Center, Northwest Minzu University, Lanzhou 730030, Gansu, China \\ ${ }^{2}$ College of Life Science and Engineering, Northwest Minzu University, Lanzhou 730030, Gansu, China \\ ${ }^{3}$ Department of Biosystems Engineering, Zhejiang University, 886 Yuhangtang Road, Hangzhou 310058, Zhejiang, China \\ ${ }^{4}$ Gannan Research Institute of Yak Milk, 32 Huanxi Road, Hezuo 747000, Gansu, China
}

Correspondence should be addressed to Zhongren Ma; mzr@xbmu.edu.cn

Received 2 November 2019; Revised 6 January 2020; Accepted 22 January 2020; Published 4 March 2020

Academic Editor: Alejandro Hernández

Copyright ( $\odot 2020$ Xiaojing Tian et al. This is an open access article distributed under the Creative Commons Attribution License, which permits unrestricted use, distribution, and reproduction in any medium, provided the original work is properly cited.

The effect of storage time and packing method on dried Lycium fruits was studied through an electronic olfactory system with the metal oxide sensor array that provides an overall perception of the volatile compounds presented in the sample headspace. Principle component analysis (PCA), canonical discriminant analysis (CDA), and cluster analysis (CA) were used for freshness and packing methods discrimination of dried Lycium fruits. The stale samples of 2015 and 2016 could be separated with those of 2017 by PCA, CDA, and CA analysis. Better discrimination results were obtained by CDA, with samples of 2015 and 2016 separated with each other. For samples of 2017, the unpackaged samples of 2017-4 were distinguished with the vacuumed samples, while samples of grade C were separated with B and D. For quantitative analysis, predictive models for prediction of the storage years of dried Lycium fruits were built with methods of partial least square (PLS) analysis, multiple linear regression (MLR), and back propagation neural network (BPNN). The model built by BPNN showed the best predict ability with $R^{2}=0.9994$, while PLS and MLR were also effective in the prediction of storage years of dried Lycium fruits, with high determination coefficients of 0.9316 and 0.9330 . These findings showed that E-nose can be used in the discrimination of the storage time and package method of dried Lycium fruits.

\section{Introduction}

Lycium barbarum L., a Solanaceae defoliated shrubbery that grows in China, Tibet, and other parts of Asia, reportedly have many health-enhancing effects, such as immune modulation, antioxidant effects, and eye health benefits $[1,2]$. The dried fruits have been used as traditional medicine in China and in many countries for more than 2500 years [3].

However, the content of the bioactive substances in dried Lycium fruits declines with storage, such as the content of Lycium barbarum polysaccharides [4], chlorogenic acid, $[5,6]$, and total flavonoids [7], indicating that stale Lycium fruits weaken in terms of pharmacodynamic effects. It is very difficult for customs to recognize the freshness of dried
Lycium fruits. Guaranteeing the quality of commercialized products of $L$. barbarum is important.

For the quality detection of dried Lycium fruits, sensory evaluation [8], physical and chemical component analysis and fingerprint technology, and spectroscopy technology are used. For sensory evaluation, it is the traditional method used for quality differentiation. However, it relies on the specialists and unable to give the content of internal components, which limits the application. For methods based on physical and chemical component analysis and fingerprint technology [9], they were effective in regional distribution $[10-12]$, variety identification, and differentiation $[13,14]$. The complex sample pretreatment, long detection cycle, and effects by external conditions could not be ignored. For spectroscopy technology, it is widely used for tracing the 
origin of $L$. barbarum $[15,16]$ varieties, and species differentiation of eight Lycium species with two-dimensional infrared spectroscopic fingerprinting have been studied [17]. However, samples were usually crushed to powder [16] to guarantee the sample homogeneity and spectral data stability. Thus, it was not a nondestructive test. The methods used to detect the quality of dried Lycium fruits could not meet the requirement of market supervision department for fast and nondestructive detection methods. It is important to develop a fast, nondestructive method to distinguish and predict the freshness of dried Lycium fruits.

The difference in the composition and content of inner components of dried Lycium fruits results in varied odors of volatiles on the surface, thereby providing a basis for the nondestructive internal quality assessment of dried Lycium fruits by using the information of volatile compounds. However, the composition of volatiles is complex and difficult to detect and analyze. Works conducted mainly focused on the composition and content of volatile compounds for Goji berry of different origins [18] and processing methods [19]. Few studies were conducted on the judgment of storage years and other factors on the freshness by using flavor compounds.

Gas sensor arrays are sensitive to the volatiles of samples and give a comprehensive odor fingerprint, which could be used for qualitative and quantitative analysis of the nondestructive freshness judgment of dried Lycium fruits. Detection of the volatile odors released from the whole-dried Lycium fruits allows the development of a fast, objective, and nondestructive method for rapid evaluation of the freshness of dried Lycium fruits in the market. Electronic nose (Enose) is a device developed for sensing of odor information by using a gas sensor array that is sensitive to volatile compounds released from the whole sample. With the advantages of simple sample preparation, high sensitivity, reliability, and repeatability, E-nose has been widely used in food and agricultural products for quality control, environmental monitoring, medical diagnosis, explosive detection, and other fields.

Preliminary studies on E-nose have been conducted on agricultural products used for medicine and food. The E-nose was used for variety differentiation and identification. It was used for determination of the difference between American and Asian ginseng [20], as well as variety differentiation of three cultivars of Perilla frutescens [21], 10 different varieties of Chinese jujubes [22], and 13 species of Chinese medicine ([23]. For origin traceability, Radix Angelica sinensis (Danggui) from 4 different producing areas were distinguished by the E-nose [24]. In addition, raw samples of Licorice roots were classified according to their origin with the help of the E-nose [25]. For the identification of processing methods for products used for medicine and food, differences between fresh and steamed Arctium lappa L. [26] and stir-fried processed Crataegus in different degrees [27] were effectively determined by the E-nose. For quantification prediction, the correlation between the Eurycoma longifolia extract content and E-nose response was studied [28], and an effective predictive model for rapidly identifying total glucosinolate content in Maca was built
[29]. Moreover, coupled with back propagation-artificial neural networks, the E-nose showed high ability to predict ginseng age [30].

Recently, the E-nose was used to identify production areas of Zhongning goji berries [31]. However, the smell of dried Lycium fruits was seldom employed for freshness detection, and few studies were conducted on the correlation between E-nose sensor responses and the freshness of dried Lycium fruits.

Dried Lycium fruits that differed in freshness were detected using the E-nose to do the following: (1) to evaluate the changes in odor of Lycium fruits due to differences in freshness; (2) to analyze the correlation between odor and freshness of Lycium fruits; and (3) to provide references and establish a new method for market surveillance of dried Lycium fruits.

\section{Materials and Methods}

2.1. Dried Lycium Fruit Samples. The fruits of cultivated $L$. barbarum were dried naturally immediately after picking. The dried Lycium fruits were collected from June to September in 2015, 2016, and 2017 in Zhongning, Ningxia Hui Autonomous Region, China. As listed in Table 1, sample 1 was produced in the year 2015, sample 2 was produced in the year 2016, and samples 3-6 were produced in the year 2017 with different grades. The samples were stored for 3, 2, and 1 years, respectively. Each kind of dried Lycium fruits were sealed in two zipper bags, and then stored at $4^{\circ} \mathrm{C}$ in the refrigerator to prevent moisture absorption and softening of the dried fruits.

All the dried Lycium fruit samples were brought to room temperature before E-nose detection. In addition, $31 \mathrm{du}-$ plications were prepared for each kind of samples. 1 2 responses were eliminated as the E-nose needs time to adapt to a new sample.

2.2. Electronic Nose (E-Nose). To obtain the odor of volatiles emitted from dried Lycium fruits, an E-nose of PEN2 (Airsense Corporation, Germany) was used. The E-nose system consists of three parts, namely, a sensor array, a detector unit, and a pattern recognition system. The nomenclature and characteristics of the 10 metal oxide sensors are listed in Table 2, showing that each sensor has a certain degree of affinity toward specific chemical or volatile compounds. The software Win Muster v.1.6 was used for data recording.

In our former study, the experimental conditions for the detection of dried Lycium fruits by the E-nose were optimized [32] and given as follows. Before detected by the E-nose, the dried Lycium fruit samples were brought to room temperature. The headspace used for the detection of E-nose was generated by the following processes. Without any preparation, $20.0 \mathrm{~g}$ of the dried Lycium fruits was placed in a beaker $(500 \mathrm{~mL})$. The beaker was sealed by a plastic and kept for $30 \mathrm{~min}$ at room temperature of $25^{\circ} \mathrm{C} \pm 3^{\circ} \mathrm{C}$ for the headspace to stabilize. During sampling, the stabilized headspace was transferred into the sensor chamber at a flow 
TABLE 1: The profiles of dried Lycium fruits samples.

\begin{tabular}{cccccccc}
\hline No. & Samples & Producing year & $\begin{array}{c}\text { Granularity } \\
(\mathrm{seed} / 50 \mathrm{~g})\end{array}$ & Package method & $\begin{array}{c}\text { Storage time } \\
(\text { years })\end{array}$ & $\begin{array}{c}\text { Dry weight of } 100 \text { seeds } \\
(\mathrm{g})\end{array}$ & $\begin{array}{c}\text { Grade } \\
(\text { seeds/50 g) }\end{array}$ \\
\hline 1 & 2015 & 2015 & $396 \pm 13$ & Vacuum packaged & 3 & $12.4 \pm 0.75$ & $\mathrm{C}(\leq 580)$ \\
2 & 2016 & 2016 & $386 \pm 22$ & Vacuum packaged & 2 & $13.19 \pm 0.51$ & $\mathrm{C}(\leq 580)$ \\
3 & $2017-1$ & 2017 & $392 \pm 3$ & Vacuum packaged & 1 & $12.55 \pm 0.45$ & $\mathrm{C}(\leq 580)$ \\
4 & $2017-2$ & 2017 & $328 \pm 2$ & Vacuum packaged & 1 & $15.09 \pm 0.78$ & $\mathrm{~B}(\leq 370)$ \\
5 & $2017-3$ & 2017 & $663 \pm 4$ & Vacuum packaged & 1 & $7.67 \pm 0.30$ & $\mathrm{D}(\leq 900)$ \\
6 & $2017-4$ & 2017 & $425 \pm 5$ & Bulk packaged & 1 & $11.89 \pm 0.30$ & $\mathrm{C}(\leq 580)$ \\
\hline
\end{tabular}

TABLE 2: Sensors used and their main applications in PEN 2 electronic nose.

\begin{tabular}{|c|c|c|c|}
\hline $\begin{array}{l}\text { Number in } \\
\text { array }\end{array}$ & Sensor name & General description & Reference \\
\hline S1 & W1C-aromatic & Aromatic compounds & $\begin{array}{l}\text { Toluene, } \\
10 \mathrm{ppm}\end{array}$ \\
\hline S2 & $\begin{array}{l}\text { W5S-broad } \\
\text { range }\end{array}$ & $\begin{array}{c}\text { Very sensitive, broad-range sensitivity, react on nitrogen oxides, very sensitive with } \\
\text { negative signal }\end{array}$ & $\mathrm{NO}_{2}, 1 \mathrm{ppm}$ \\
\hline S3 & W3C-aromatic & Ammonia, used as sensor for aromatic compounds & $\begin{array}{l}\text { Benzene, } \\
1 \mathrm{ppm}\end{array}$ \\
\hline S4 & W6S-hydrogen & Mainly hydrogen, selectively (breath gases) & $\mathrm{H}_{2}, 100 \mathrm{ppb}$ \\
\hline S5 & $\begin{array}{l}\text { W5C-arom- } \\
\text { aliph }\end{array}$ & Alkanes, aromatic compounds, less polar compounds & $\begin{array}{c}\text { Propane, } \\
1 \mathrm{ppm}\end{array}$ \\
\hline S6 & $\begin{array}{l}\text { W1S-broad- } \\
\text { methane }\end{array}$ & Sensitive to methane (environment) ca, $10 \mathrm{ppm}$, broad range, similar to no. 8 & $\begin{array}{c}\mathrm{CH}_{4} \\
100 \mathrm{ppm}\end{array}$ \\
\hline S7 & $\begin{array}{l}\text { W1W-sulfur- } \\
\text { oganic }\end{array}$ & $\begin{array}{l}\text { Reacts on sulfur compounds, } \mathrm{H}_{2} \mathrm{~S} 0.1 \mathrm{ppm} \text {; otherwise, sensitive to many terpenes and } \\
\text { sulfur organic compounds, which are important for smell, limonene, and pyrazine }\end{array}$ & $\mathrm{H}_{2} \mathrm{~S}, 1 \mathrm{ppm}$ \\
\hline S8 & $\begin{array}{l}\text { W2S-broad- } \\
\text { alcohol }\end{array}$ & Detects alcohols, partially aromatic compounds, broad range & $\mathrm{CO}, 100 \mathrm{ppm}$ \\
\hline S9 & $\begin{array}{c}\text { W2W-sulph- } \\
\text { chlor }\end{array}$ & Aromatic compounds, sulfur organic compounds & $\mathrm{H}_{2} \mathrm{~S}, 1 \mathrm{ppm}$ \\
\hline S10 & $\begin{array}{l}\text { W3S methane- } \\
\text { aliph }\end{array}$ & Reacts on high concentration $>100 \mathrm{ppm}$, sometime very selective (methane) & $\begin{array}{c}\mathrm{CH}_{4} \\
100 \mathrm{ppm}\end{array}$ \\
\hline
\end{tabular}

rate of $300 \mathrm{~mL} \cdot \mathrm{min}^{-1}$. The detection procedure was as follows. For each sample, the measurement time was set to $70 \mathrm{~s}$ at an interval of $1 \mathrm{~s}$, and the sensors were rinsed for $80 \mathrm{~s}$ with clean air before the detection of the next sample. All the samples were detected at room temperature with 31 duplications.

2.3. Granularity and Dry Weight of 100 Seeds. The granularity and dry weight of 100 seeds, indicating the seed size, maturity, and the quality, were detected according to the national standards of [33], and the results are listed in Table 1.

2.4. Statistical Analysis. The ability of the E-nose in the evaluation of dried Lycium fruits freshness was judged by the chemometrics. Principle component analysis (PCA), canonical discriminate analysis (CDA), and cluster analysis (CA) were employed to visualize the difference of dried Lycium fruits with different freshness. To study the correlation between the storage years of the dried Lycium fruits and E-nose sensor responses, multiple linear regression (MLR) with the step regression method, partial least square (PLS) regression with cross-validation, and back propagation neural network (BPNN) were performed. And the predictive capacity of the E-nose for the storage years of dried Lycium fruits was compared. Both the qualitative and quantitive methods were compared to find the better one.

For data analysis, the SAS version 8 (SAS Institute Inc., Gary, USA) was used. The figures were plotted with Origin Pro 8.

\section{Results and Discussion}

3.1. Sensor Array Responses to Dried Lycium Fruits. The typical responses of E-nose sensors to dried Lycium fruits produced in the years 2015, 2016, and 2017 are shown in Figure 1. For one sample, each curve represents a sensor transient. For the E-nose, the output signal of each sensor is given as G/G0, where G0 represents the electronic conductivity (resistance) of sensor to the zero gas, which is ambient air after filtered by active carbon, and $G$ represents the electronic conductivity (resistance) of the sensor to the sample gas.

After an initial period of low and stable conductivity, the conductivities for sensor S2 increased sharply within the first $30 \mathrm{~s}$ and then stabilized after $50 \mathrm{~s}$ of collection time. The conductivities of sensor S6, S7, S8, and S9 increased slowly during detection. For sensors S1, S3, and S5, the conductivities dropped slightly and stabilized after $40 \mathrm{~s}$ collection time. The responses of S4 and S10 to dried Lycium fruits were 


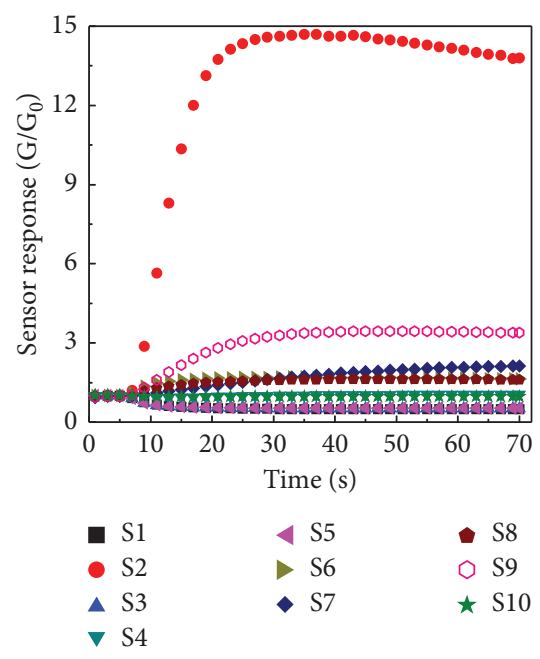

(a)

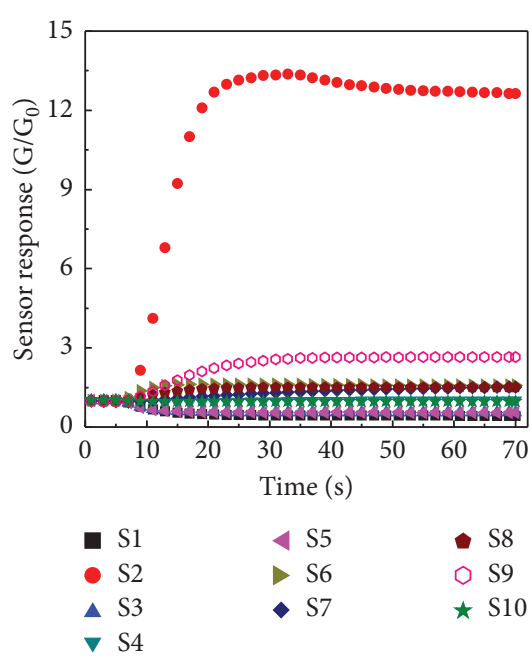

(b)

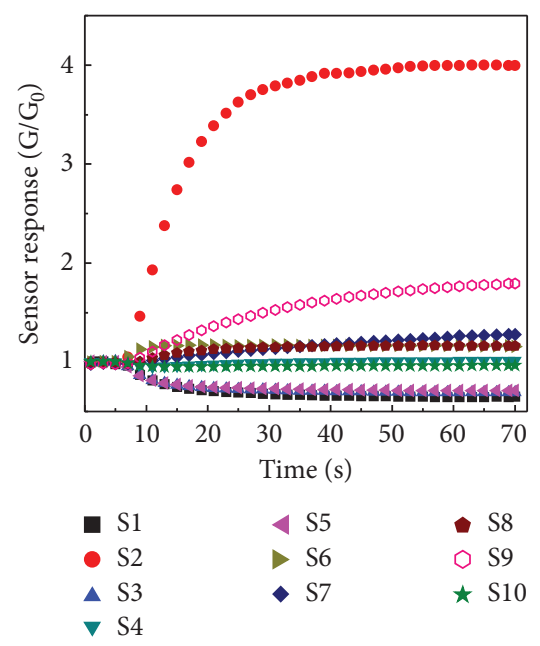

(c)

FIGURE 1: Ten sensors' response curve to the dried Lycium fruits samples with different producing years.

weak. The sensor signal stabilized generally and was considered for further analysis.

As shown in Figure 1, the response tendency of the sensors was quite similar for dried Lycium fruits produced in different years, whereas the response varied greatly in intensity for S2 and S9.

The stabilized sensor responses at the $70^{\text {th }}$ second were extracted and analyzed by ANOVA, and the results are shown in Table 3. As shown in Table 3, except for S4, the responses of sensors S1-S3 and S5-S10 were significantly affected by the producing year of dried Lycium fruits, thereby laying the foundation for the differentiation of dried Lycium fruits produced in different years.

\subsection{Discrimination Storage Years and Packing Method of} Dried Lycium Fruits with PCA and CDA. For the volatile components of dried Lycium fruit, it is reported that the nitrogenous substances, such as 6-methyl-6-nitroheptan-2one, made the responses of $\mathrm{S} 2$ changed greatly. For the high content of aldehydes, such as hexanal and 2,6,6-trimethyl-1, 3-cyclohexadiene-1-carboxaldehyde, alcohols of 1-octen-3$\mathrm{ol}$, and ketones of 2,3-butanedione, makes the responses of S8 and S6 differed with each other. For the major aromatic compounds of alkanes, furan, pyrazines, and aromatic ether, the sensors S1, S3, S5, S9, and S10 respond to these flavors. For terpenes, 10 compounds were reported, which made the response of S7 changes. Furthermore, hexanal and 1octen-3-ol, the oxidation products of fatty acids, and 2, 6, 6trimethy-1, 3-cyclohexadiene-1-carboxaldehyde, the oxidation products of carotene components, were the prime candidates of undesirable odor of dried Lycium fruits and its products. During the storage of dried Lycium fruits, the smell changed due to the oxidation, hydrolysis of carotene components, $\omega 5$ group of the $\mathrm{C} 18$ fatty acids, and other components [9]. All these changes of volatile compounds were detected by the E-nose.
The extracted sensor responses of the E-nose to dried Lycium fruits at the $70^{\text {th }}$ second were analyzed by PCA and $\mathrm{CDA}$, and the results are shown in Figure 2. In Figure 2(a), the first three PCs (PC1, PC2, and PC3) explained $97.28 \%$ of the total variance, providing most of the odor information of dried Lycium fruits. Good separation in the PC1 direction could be found for fresh Lycium fruits and stale samples. The stale samples of 2015 and 2016 could be separated with that of 2017 with PCA. Samples produced in 2015 and 2016 overlapped with one another and scattered in the right of the plot, with PC1 $>0$. Samples produced in the year 2017 scattered in the left part, with $\mathrm{PC} 1<0$. Samples of grades B and $\mathrm{D}$ overlapped with each other, they could be separated with that of grade C. For samples of grade C, different package affected the freshness of dried Lycium fruits, and samples of 2017-1 (vacuum packaged) and 2017-4 (bulk packaged) were separated.

With PCA, the stale fruits and different grades of Lycium fruits can be discriminated; the same results were obtained by the taste information obtained by the taste sensing system with artificial lipid-based membrane sensors in our former studies [34]. The ability of the E-nose to discriminate staledried Lycium fruits from fresh ones provided a new nondestructive method for the detection of adulteration of dried Lycium fruits with stale ones.

The CDA results were shown in Figure 2(b). Can1, Can2, and Can 3 explained $96.02 \%$ of the total variance with the value of $100 \%$. Thus, the first three CANs can give most information of the E-nose data set. The samples were grouped into three clusters according to the producing year. The stale samples of 2015 and 2016 could be separated with that of 2017 with CDA. And the 2015 and 2016 samples were discriminated from each other, and results were better than those of PCA. For samples produced in the year 2017, the CDA results were similar with that of PCA. With different freshness of dried Lycium fruits, the smell changed with the producing year. This observation could be used in the 
TABle 3: Results of ANOVA.

\begin{tabular}{lccccccccccc}
\hline Factors & & S1 & S2 & S3 & S4 & S5 & S6 & S7 & S8 & S9 & S10 \\
\hline \multirow{2}{*}{ Producing year } & F & 425.74 & 544.96 & 379.27 & 0.8 & 338.29 & 348.68 & 40.40 & 420.24 & 125.96 & 216.66 \\
& Sig. & $<0.0001$ & $<0.0001$ & $<0.0001$ & 0.4984 & $<0.0001$ & $<0.0001$ & $<0.0001$ & $<0.0001$ & $<0.0001$ & $<0.0001$ \\
\hline
\end{tabular}

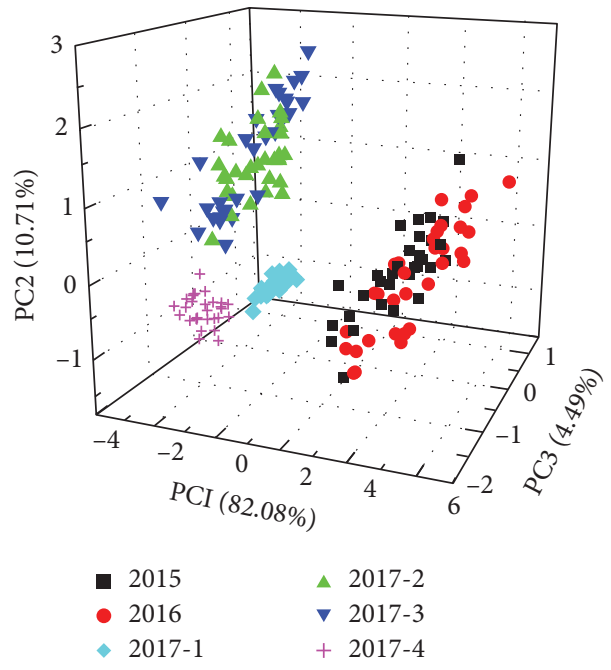

(a)

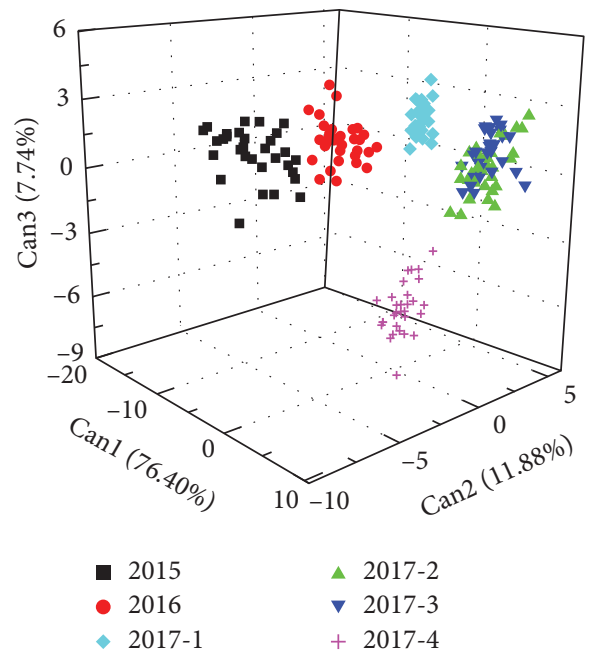

(b)

FIgUre 2: (a) PCA and (b) CDA scatter plot of dried Lycium fruits produced in different years based on E-nose responses.

discrimination of adulteration of dried Lycium fruits with stale ones.

\subsection{Classification of Storage Years and Packing Method of} Dried Lycium Fruit with CA. For dried Lycium fruits, CA was conducted based on odor information. The dendrogram obtained by CA is shown in Figure 3.

In Figure 3, the results obtained by CA showed that, at the distance $D=1.3711$, the samples of dried Lycium fruits were clustered into two groups, namely, cluster 1 (the stale samples of 2015 and 2016) and cluster 2 (the four samples produced in 2017). For cluster 1, samples of 2015 and 2016 could not be discriminated. For cluster 2, the samples of 2017-1 and 2017-4 were discriminated with others at the distance of 0.7301. However, 2017-2 and 2017-3 could not be distinguished from each other, similar to the PCA results.

With sensor responses, the E-nose system could recognize the fresh and stale fruits of dried Lycium fruits by PCA, CDA, and CA methods.

\subsection{Rapid Characterization of Storage Years of Dried Lycium} Fruits. To establish the relationship between the responses of E-nose and storage years of dried Lycium fruits, analytical methods of MLR, PLS, and BPNN were used, and the results were compared to find the best predictive model.

Data set containing dried Lycium fruit samples (156 for calibration and 22 for validation) was used to build the predictive model for the storage years of dried Lycium fruits. The correlation coefficient $\left(R^{2}\right)$ and root mean square error (RMSE) between predicted and experimental values (RMSE) were used to evaluate the model performance. Large $R^{2}$ and low RMSE lead to good calibration model. The results are shown in Figure 4 and Table 4.

With the stepwise method, the MLR algorithm established a model that describes the relationship between the E-nose sensor signals and the storage years of dried Lycium fruits. The predictive models for storage years of dried Lycium fruits were given as follows.

Storage years of dried Lycium fruits $=9.873 \times \mathrm{S} 1-$ $31.187 \times \mathrm{S} 3+19.800 \times \mathrm{S} 5-3.476 \times \mathrm{S} 7+2.576 \times \mathrm{S} 9+12.132 \times$ S10 - 9.506 .

Large $R^{2}$ and low RMSE indicate adequate fits. As shown in Table 4, the predictive ability of the E-nose was listed. A linear correlation was observed between the responses of E-nose sensors and the storage years of dried Lycium fruits. When the model was used to predict the storage years of dried Lycium fruits in the test data set, $R^{2}$ was 0.9239 , thereby showing good ability to predict the storage years of dried Lycium fruits.

For models built by PLS, the coefficient $R^{2}=0.9316$ was found between the E-nose sensor responses and storage years of dried Lycium fruit samples. When the model was used to predict samples in the test set, $R^{2}$ of 0.9480 was obtained. For the prediction of storage years of dried Lycium fruits, the PLS methods are slightly better than that of MLR.

For BPNN, the experimental design was completely randomized with each sample as an experimental unit. The architecture of the chosen artificial neural network was $N \times(2 N+1) \times M$ three-layer back propagation. The input layer, i.e., one hidden layer, was designed as 10 neurons according to the sensor array of 10 sensors. The output layer 


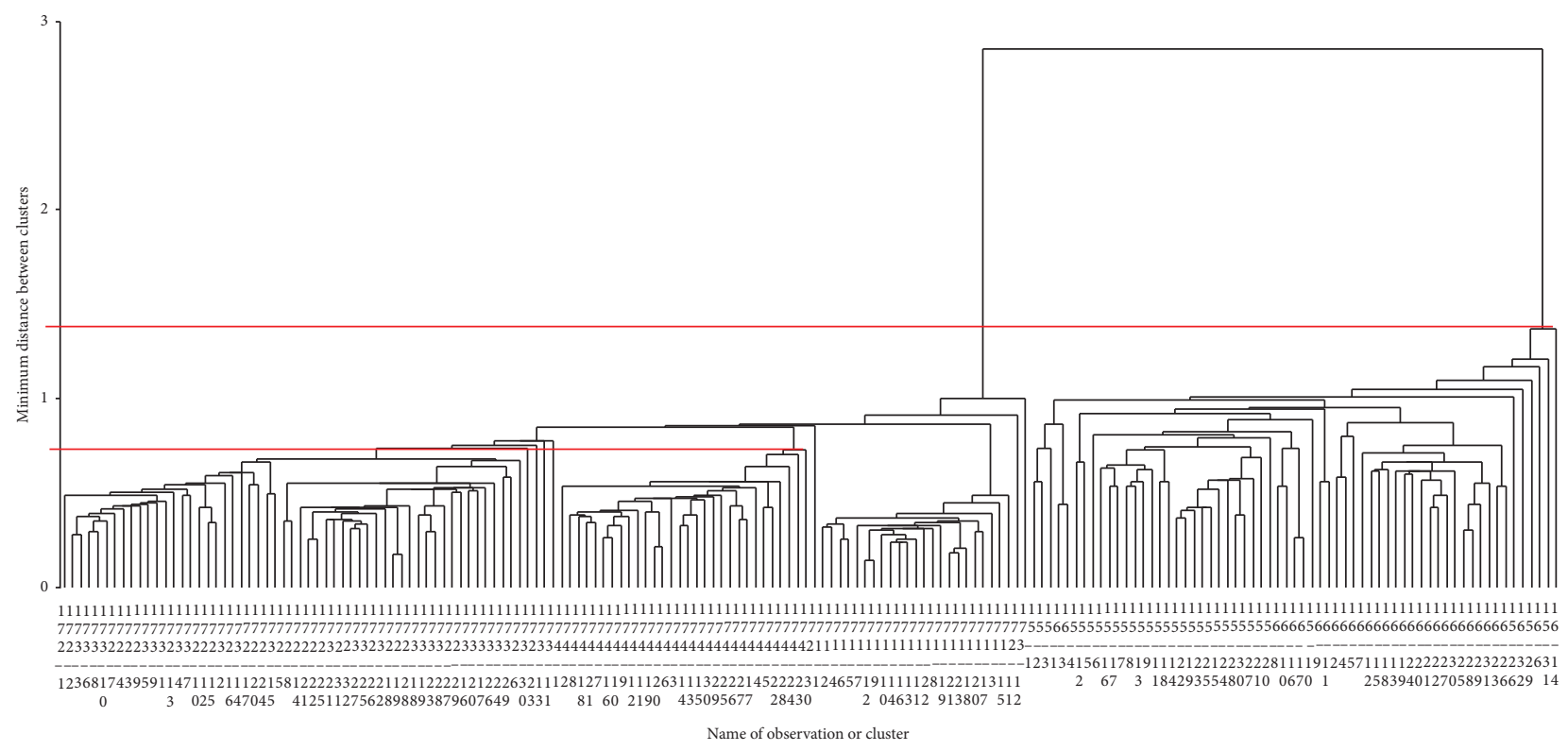

FIgURE 3: Tree diagram from CA by minimum distance with smell information.

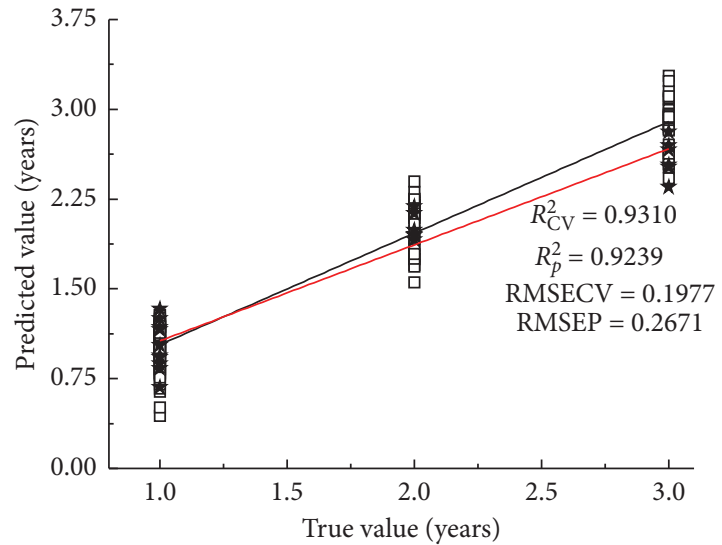

$\square$ Train

$\star$ Test

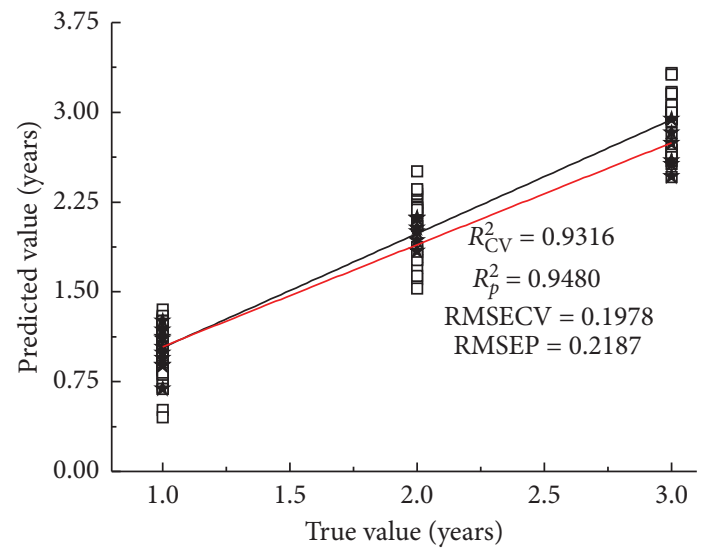

$\square$ Train

\ Test

(b)

(a)

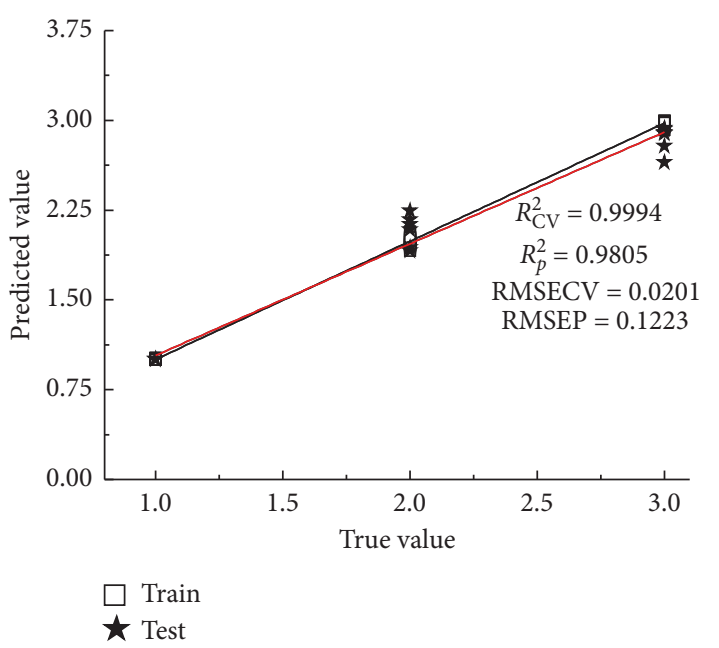

(c)

FIgURE 4: Prediction storage years of dried Lycium fruits by MLR, PLS, and BPNN. 
TABle 4: Comparison of three quantitative prediction methods for storage years of dried Lycium fruits.

\begin{tabular}{lcccc}
\hline \multirow{2}{*}{ Prediction methods } & \multicolumn{2}{c}{ Training set } & \multicolumn{2}{c}{ Test set } \\
& $R_{\mathrm{cv}}^{2}$ & RMSEC (\%) & $R_{p}^{2}$ & RMSEP (\%) \\
\hline MLR & 0.9310 & 0.1977 & 0.9239 & 0.2671 \\
PLS & 0.9316 & 0.1978 & 0.9480 & 0.2187 \\
BPNN & 0.9994 & 0.0201 & 0.9805 & 0.1223 \\
\hline
\end{tabular}

had three neurons for different storage years of Lycium fruits.

The results obtained by the training model of BPNN showed that all the training and testing samples were correctly classified according to the storage years of Lycium fruits. Moreover, the correlations between the observed and predicted storage years of dried Lycium fruits were higher than 0.98 (Table 4) for the training and testing sets. The low errors of prediction and the high correlation of the BPNN model suggested that the E-nose can be successfully applied to the determination of the storage years of dried Lycium fruits. The BPNN-E-nose methods were suitable for the prediction of storage age for wheat [35-37].

In conclusion, the best results were obtained by the BPNN model, with high correlation (higher than 0.98) for the training and testing subsets.

For the E-nose, it has shown it ability in the discrimination of dried Lycium fruits for the freshness and the packing methods and also in the prediction of storage years. Former studies were conducted on the Lycium ruthenicum Murr., for producing area, species, and drying conditions [38]. In the future, more applications of the E-nose on quality detection should be studied to give more objective results.

\section{Conclusions}

Multivariate techniques (PCA, CDA, and CA) were used to prove the E-nose's usefulness for discriminating dried Lycium fruits according to freshness. Among the three methods, CDA was suitable for the freshness differentiation of dried Lycium fruits according to the producing year. Strong correlation was observed between the E-nose response and freshness of dried Lycium fruits, and BPNN was the most suitable for the prediction of storage years. The results obtained by this study are promising in terms of further development of rapid and nondestructive detection methods based on E-nose systems for discrimination between dried Lycium fruits and stale ones.

\section{Data Availability}

The research data about this manuscript used to support the findings of this study are included within the article.

\section{Disclosure}

This study has used the E-nose for nondestructive detection of dried Lycium fruit freshness, which provides a method to evaluate the quality of Lycium fruit.

\section{Conflicts of Interest}

The authors declare that they have no conflicts of interest.

\section{Authors' Contributions}

M. L. and Y. L. carried out experimentation; X. T. and Z. W. were responsible for data analysis; X. T. and J. W. acquired funding. X. T. and Z. M. investigated the study; S. C., P. Z., X. B., L. S., and L. L. wrote, reviewed, and edited the manuscript.

\section{Acknowledgments}

This research was funded by the National Natural Science Foundation of China through Project 31560477, National Natural Science Foundation of Gansu Province through Project 18JR3RA371, Gansu Province Science and Technology funding plan through Project 17YF1WA166, and Ministry of Science and Technology Assistance Project through Project KY201501005.

\section{Supplementary Materials}

Graphical Abstract (Supplementary Materials)

\section{References}

[1] H. Amagase and N. R. Farnsworth, "A review of botanical characteristics, phytochemistry, clinical relevance in efficacy and safety of Lycium barbarum fruit (goji)," Food Research International, vol. 44, no. 7, pp. 1702-1717, 2011.

[2] N. P. Seeram, "Berry fruits: compositional elements, biochemical activities, and the impact of their intake on human health, performance, and disease," Journal of Agricultural and Food Chemistry, vol. 56, no. 3, pp. 627-629, 2008.

[3] D. Donno, G. L. Beccaro, M. G. Mellano, A. K. Cerutti, and G. Bounous, "Goji berry fruit (Lycium spp.): antioxidant compound fingerprint and bioactivity evaluation," Journal of Functional Foods, vol. 18, pp. 1070-1085, 2015.

[4] X. Y. Wang, L. Ying, and Y. P. Liu, "The preliminary interpretation about the chemical material base of oil-spilling in lycii fructus. 5," Pharmacy and Clinics of Chinese Materia Medica, vol. 3, no. 5, pp. 1-2, 2012, in Chinese.

[5] W. Yang and G. L. Liao, "Determination of chlorogenic acid in Lycium barbarum L. From different habitats by HPLC," Chinese Journal of Modern Drug Application, vol. 2, no. 1, pp. 51-53, 2008, in Chinese.

[6] Z. Zhang, G. L. Liao, and X. W. Shi, "Determination of chlorogenic acid and rutin in Lycium barbarum L. From different habitats by HPLC," Lishizhen Medicine and Materia Medica Research, vol. 18, no. 7, pp. 1586-1587, 2007, in Chinese.

[7] Y. Liu, M. Long, X. Tian, F. Zhang, S. Chen, and Z. Ma, "Extraction process optimization and determination of total flavonoids in Chinese wolfbery in different years," Journal of Northwest Minzu University (Natural Science), vol. 40, no. 115 , pp. 70-75, 2019, in Chinese.

[8] R. Yao, M. Heinrich, Y. Zou et al., "Quality variation of goji (fruits of Lycium spp.) in China: a comparative morphological and metabolomic analysis," Frontiers in Pharmacology, vol. 9, p. 151, 2018. 
[9] J.-S. Kim and H. Y. Chung, "GC-MS analysis of the volatile components in dried boxthorn (Lycium chinensis) fruit," Journal of the Korean Society for Applied Biological Chemistry, vol. 52, no. 5, pp. 516-524, 2009.

[10] I. Bondia-Pons, O. Savolainen, R. Törrönen, J. A. Martinez, K. Poutanen, and K. Hanhineva, "Metabolic profiling of goji berry extracts for discrimination of geographical origin by non-targeted liquid chromatography coupled to quadrupole time-of-flight mass spectrometry," Food Research International, vol. 63, pp. 132-138, 2014.

[11] L. Cossignani, F. Blasi, M. S. Simonetti, and D. Montesano, "Fatty acids and phytosterols to discriminate geographic origin of Lycium barbarum berry," Food Analytical Methods, vol. 11, no. 4, pp. 1180-1188, 2018.

[12] W. Lu, Q. Jiang, H. Shi, Y. Niu, B. Gao, and L. Yu, "Partial least-squares-discriminant analysis differentiating Chinese wolfberries by UPLC-MS and flow injection mass spectrometric (FIMS) fingerprints," Journal of Agricultural and Food Chemistry, vol. 62, no. 37, pp. 9073-9080, 2014.

[13] T. Islam, X. Yu, T. S. Badwal, and B. Xu, "Comparative studies on phenolic profiles, antioxidant capacities and carotenoid contents of red goji berry (Lycium barbarum) and black goji berry (Lycium ruthenicum)," Chemistry Central Journal, vol. 11, no. 1, p. 8, 2017.

[14] G. Li, J. You, Y. Suo et al., "A developed pre-column derivatization method for the determination of free fatty acids in edible oils by reversed-phase HPLC with fluorescence detection and its application to Lycium barbarum seed oil," Food Chemistry, vol. 125, no. 4, pp. 1365-1372, 2011.

[15] Y. Gao, X. Yu, L. Xu, N. Wang, and R. Zhang, "A novel approach to discriminate Lycium barbarum from the Zhongning area using FT-IR spectroscopy and chemometrics," Analytical Methods, vol. 7, no. 21, pp. 9108-9113, 2015.

[16] T. T. Shen, X. B. Zou, J. Y. Shi et al., "Determination geographical origin and flavonoids content of goji berry using near-infrared spectroscopy and chemometrics," Food Analytical Methods, vol. 9, no. 1, pp. 68-79, 2016.

[17] X. Yao, Y. Peng, Q. Zhou, P. Xiao, and S. Sun, "Distinction of eight lycium species by fourier-transform infrared spectroscopy and two-dimensional correlation IR spectroscopy," Journal of Molecular Structure, vol. 974, no. 1-3, pp. 161-164, 2010.

[18] S. T. Lou, H. Cheng, W. W. Lin et al., "Analysis of volatile components of Lycium ruthenicum Murr. by SPME-GC/MS," Journal of Chinese Institute of Food Science and Technology, vol. 16, no. 10, pp. 245-250, 2016, in Chinese.

[19] L. Xie, A. S. Mujumdar, Q. Zhang et al., "Pulsed vacuum drying of wolfberry: effects of infrared radiation heating and electronic panel contact heating methods on drying kinetics, color profile, and volatile compounds," Drying Technology, vol. 35, no. 11, pp. 1312-1326, 2017.

[20] S. Cui, J. Wu, J. Wang, and X. Wang, "Discrimination of American ginseng and Asian ginseng using electronic nose and gas chromatography-mass spectrometry coupled with chemometrics," Journal of Ginseng Research, vol. 41, no. 1, pp. 85-95, 2017.

[21] M. Laureati, S. Buratti, A. Bassoli, G. Borgonovo, and E. Pagliarini, "Discrimination and characterisation of three cultivars of Perilla frutescens by means of sensory descriptors and electronic nose and tongue analysis," Food Research International, vol. 43, no. 4, pp. 959-964, 2010.

[22] Q. Chen, J. Song, J. Bi, X. Meng, and X. Wu, "Characterization of volatile profile from ten different varieties of Chinese jujubes by HS-SPME/GC-MS coupled with E-nose," Food Research International, vol. 105, pp. 605-615, 2018.

[23] D. Li, T. Lei, S. Zhang, X. Shao, and C. Xie, "A novel headspace integrated E-nose and its application in discrimination of Chinese medical herbs," Sensors and Actuators B: Chemical, vol. 221, pp. 556-563, 2015.

[24] S. Zheng, W. Ren, and L. Huang, "Geoherbalism evaluation of radix Angelica sinensis based on electronic nose," Journal of Pharmaceutical and Biomedical Analysis, vol. 105, pp. 101106, 2015

[25] M. Russo, D. Serra, F. Suraci, R. Di Sanzo, S. Fuda, and S. Postorino, "The potential of e-nose aroma profiling for identifying the geographical origin of licorice (Glycyrrhiza glabra L.) roots," Food Chemistry, vol. 165, pp. 467-474, 2014.

[26] H. S. Ren, Y. Y. Zheng, R. X. Zhao et al., "The volatile component analysis of Arctium iappa L. based on electronic nose and gas chromatography-mass spectrometry," Journal of Shandong University, vol. 30, pp. 6-12, 2017, in Chinese.

[27] T. Yang, S. Yang, L. Li, C. Wu, L. J. L. M. AI, and M. Research, "Study on discriminating stir-fried processed crataegus in different degree based on electronic nose and machine vision," Lishizhen Medicine and Materia Medica Research, vol. 25, no. 10, pp. 2399-2402, 2014.

[28] A. Islam, Z. Ismail, B. Saad, A. R. Othman, M. N. Ahmad, and A. Y. M. Shakaff, "Correlation studies between electronic nose response and headspace volatiles of Eurycoma longifolia extracts," Sensors and Actuators B-Chemical, vol. 120, no. 1, pp. 245-251, 2006.

[29] Y. T. Dang, P. Yuan, K. Xia et al., "Rapid identification of maca quality based on odor fingerprint," Food Science, vol. 39, no. 6, pp. 291-297, 2018, in Chinese.

[30] S. Cui, J. Wang, L. Yang, J. Wu, and X. Wang, "Qualitative and quantitative analysis on aroma characteristics of ginseng at different ages using E-nose and GC-MS combined with chemometrics," Journal of Pharmaceutical and Biomedical Analysis, vol. 102, pp. 64-77, 2015.

[31] Q. Li, X. Yu, L. Xu, and J.-M. Gao, "Novel method for the producing area identification of Zhongning goji berries by electronic nose," Food Chemistry, vol. 221, pp. 1113-1119, 2017.

[32] X. J. Tian, J. Wang, Z. R. Ma et al., "Identification of the geographical origin for wolfberry by an electronic nose in combination with multivariate analysis," Acta Agriculturae Zhejiangensis, vol. 30, pp. 1604-1611, 2018, in Chinese.

[33] GB/T18672, National Standard of the People's Republic of China: Lycium (Dried Lycium Berry), New World Press, Beijing, China, 2002.

[34] X. Tian, J. Wang, S. Cui et al., "Taste characterization for the quality assessment of dried lycium fruits," Journal of Food Quality, vol. 38, no. 2, pp. 103-110, 2015.

[35] C. Apetrei, I. M. Apetrei, I. Nevares et al., "Using an e-tongue based on voltammetric electrodes to discriminate among red wines aged in oak barrels or aged using alternative methods," Electrochimica Acta, vol. 52, no. 7, pp. 2588-2594, 2007.

[36] L. Pang, J. Wang, X. Lu, and H. Yu, "Discrimination of storage age for wheat by E-nose," Transactions of the Asabe, vol. 51, no. 5, pp. 1707-1712, 2008.

[37] A. Rudnitskaya, E. Polshin, D. Kirsanov et al., "Instrumental measurement of beer taste attributes using an electronic tongue," Analytica Chimica Acta, vol. 646, no. 1-2, pp. 111-118, 2009.

[38] L. Song, Evaluation for Flavor of Lycium Ruthenicum Murr. By Electronic Nose and Electronic Tongue, Tianjin University of Commerce, Tianjin, China, 2018, in Chinese. 